\title{
A CONVENÇÃO-QUADRO SOBRE MUDANÇAS CLIMÁTICAS E AS RESPONSABILIZAÇÕES DOS ESTADOS PELA REDUÇÃO DA EMISSÃO DOS GASES DE EFEITO ESTUFA
}

\author{
Thaís da Silva Gularte* \\ Rafael Santos de Oliveira**
}

RESUMO: O presente artigo trata do aquecimento global e das responsabilidades comuns mas diferenciadas dos países partes da Convenção sobre Mudança do Clima, criada para combater a mudança climática. Relatando os principais mecanismos para a estabilização dos gases de efeito estufa, evitando a interferência perigosa para a humanidade e para o meio ambiente.

PALAVRAS-CHAVE: Mudanças climáticas. Estabilização dos gases de efeito estufa. Responsabilização diferenciada dos Estados

ABSTRACT: The present article treats the global heating and the common responsibilities me them differentiated of the countries parts of the Convention on Change of the Climate, created to fight the climatic change. Reporting the principal mechanisms for the stabilization of the gases of greenhouse effect, avoiding the dangerous interference for the humanity and for the environment.

KEY-WORDS: Climatic changes. Stabilization of the gases of greenhouse effect. Responsabilização differentiated of the States

* Acadêmica do Curso em Direito do Centro Universitário Franciscano (UNIFRA-RS)

**Doutorando no Curso de Pós-graduação em Direito da Universidade Federal de Santa Catarina (CPGD/UFSC). Bacharel em Direito e Mestre em Integração Latino-americana (Direito da Integração) pela Universidade Federal de Santa Maria (UFSM). Advogado e Professor do Curso de Direito do Centro Universitário Franciscano (UNIFRA) em Santa Maria - RS. rafael.oliveira@ via-rs.net 


\section{INTRODUÇÃO}

Evidências científicas demonstram a correlação entre o aquecimento global e a concentração de gases causadores do efeito estufa emitidos pelo homem, na atmosfera. A mudança climática corresponde a um dos piores problemas da humanidade no século XXI, podendo acarretar efeitos negativos aos recursos naturais e a humanidade.

Em razão das previsões de alteração climática, devido principalmente à ação antrópica e após reiteradas negociações, a Convenção-Quadro das Nações Unidas sobre Mudança do Clima foi assinada em 1992, durante a ECO/92. A Convenção estabelece como princípio fundamental a responsabilidade comum mas diferenciada dos países partes. Destarte, confere obrigações diferenciadas para os países desenvolvidos, considerados os maiores poluidores, e para os Estados em vias de desenvolvimento, mais vulneráveis aos efeitos da mudança do clima.

\section{A PROLIFERAÇÃO DE GASES DE EFEITO ESTUFA E O AQUECIMENTO GLOBAL}

A mudança climática do Planeta é uma preocupação crescente da humanidade. $\mathrm{O}$ aumento da proliferação dos gases de efeito estufa, causado, na sua maioria, pela ação do homem, ameaça a atmosfera e, conseqüentemente, pode provocar a elevação do clima da Terra. O índice crescente da emissão dos gases de efeito estufa, responsáveis pelo aquecimento global, tem como causa principal a proliferação dos gases pelas indústrias e automóveis.

$\mathrm{O}$ aumento da temperatura decorre da presença de dióxidos de carbono e gases análogos, produzidos pela queima de combustíveis fósseis, como o gás natural e o carvão, na atmosfera, que retêm o calor. Trata-se, desse modo, dos mais freqüentes meios de geração de energia. Esse efeito é exacerbado pela poluição dos mares e oceanos e pela diminuição das florestas, considerados sumidouros naturais dos dióxidos de carbono (SOARES, 2003).

$\mathrm{O}$ efeito estufa se refere às emissões de dióxido de carbono $(\mathrm{CO} 2)$ e outros gases como metano $(\mathrm{CH} 4)$ e óxido nitroso $(\mathrm{NO} 2)$ na atmosfera. O dióxido de carbono é o gás mais emitido na atmosfera e o maior responsável pelo aquecimento global, visto que suas emissões correspondem a 55\% do total das emissões globais de gases de efeito estufa. O tempo de permanência desses gases na atmosfera é de 100 anos, no mínimo, havendo, dessa forma, longa duração e a possibilidade de gerar impactos pode estender por séculos (ÁRVORES, 2007). 
A mudança climática poderá causar danos de intenso impacto para o ambiente global, como a perda de espécies animais e vegetais, o aumento de tempestades e enchentes e a transformação de ecossistemas, se não forem estabilizados os níveis de emissão dos gases de efeito estufa.

\section{NEGOCIAÇÕES}

Inserido neste paradigma alarmante da possibilidade de alterações do clima na Terra, em 1988, ascenderam-se as preocupações em relação ao clima, principalmente quanto aos prováveis efeitos a serem causados. E a mudança climática ingressou no debate político internacional, inicialmente, com o Programa Ambiental das Nações Unidas, o PNUMA, e a Secretaria Meteorológica Mundial que fundaram o Painel Intergovernamental sobre Mudanças Climáticas, o IPCC. O Painel Intergovernamental sobre Mudanças Climáticas foi criado com o objetivo de analisar e publicar a cada cinco anos, um relatório acerca dos aspectos científicos da alteração climática, bem como, dos efeitos gerados ao ambiente global e das estratégias de respostas dos Estados (SOARES, 2003).

Posteriormente sucedeu-se, o Relatório de Bruntland, antecessor aos trabalhos preparatórios da Conferência do Rio de Janeiro sobre Meio Ambiente e Desenvolvimento, que evidenciou o desenvolvimento sustentável, conceituando-o como um desenvolvimento que garante as necessidades do presente sem atingir a capacidade das gerações futuras (SILVA, 2002).

O relatório mencionado foi utilizado como base para os trabalhos da ECO/92, e, dessa forma, já estava consubstanciada a necessidade de implementação do desenvolvimento sustentável com vistas a uma maior proteção ao meio ambiente.

Nesse aspecto, tendo como base o contexto de ameaça da mudança do clima, a Assembléia Geral das Nações Unidas providenciou a criação de um tratado a respeito do tema, em virtude do primeiro relatório de avaliação do Painel Intergovernamental de Mudanças Climáticas. As negociações iniciarem-se em 1990 e terminaram durante a Conferência do Rio de Janeiro sobre Meio Ambiente e Desenvolvimento, em 1992. Destarte, a Convenção-Quadro das Nações Unidas sobre Mudanças Climáticas estava aberta para assinaturas na Cúpula da Terra, ou seja, na ECO/ 92 (SOARES, 2003).

A Conferência do Rio de Janeiro sobre Meio Ambiente e Desenvolvimento foi realizada com fulcro no estabelecimento de novos níveis de cooperação entre os Estados, bem como, na conclusão de acordos internacionais que visassem o respeito dos 
interesses de todos e protegessem a integridade do sistema global de meio ambiente e desenvolvimento (BRASIL, 2007 a).

\section{A CONVENÇÃO SOBRE MUDANÇA DO CLIMA}

A Convenção sobre Mudança Climática foi assinada por aproximadamente 154 países e uma organização internacional de integração econômica regional, a Comunidade Européia. O objeto da convenção é a criação de normas para reduzir o lançamento de todos os gases de efeito estufa ainda não regulados pelo Protocolo de Montreal (SILVA, 2002).

\section{Conforme Peter Singer:}

Como sugere seu nome, ela estabelece apenas os fundamentos para ações futuras, mas pede que as emissões dos gases do efeito estufa seja estabilizada num nível seguro, dizendo que as partes signatárias da convenção façam isso "com eqüidade e de acordo com suas responsabilidades comuns, mas suas capacidades diferenciadas". As nações desenvolvidas devem "assumir a liderança do combate à mudança climática e a seus efeitos adversos" (2004, p. 28).

Dessa forma, por Convenção-quadro entende-se um tratado ou convenção internacional disposto por texto programático e com dispositivos que devem ser complementados pelas decisões do órgão estabelecido pela convenção, como o órgão da Conferência das Partes da Convenção sobre Mudanças Climáticas. Este órgão tem como função a complementação, regulação e inovação dos dispositivos da convenção (SOARES, 2003).

A Convenção foi concebida, então, de forma a permitir que os países reforcem ou enfraqueçam o tratado de acordo com novos avanços científicos. Como exemplificadamente, eles podem concordar em tomar ações mais específicas aprovando "emendas" ou "protocolos" à Convenção (BRASIL, 2007 b).

A Convenção-Quadro foi criada com o objetivo de alcançar a estabilização das concentrações de gases de efeito estufa na atmosfera num nível que impossibilitasse a interferência perigosa induzida pelo homem no sistema climático. A convenção não determina a maneira de alcançar seus objetivos, entretanto, dispõe acerca de mecanismos de negociação (DIAS, 2004).

Apresenta como princípio fundamental a proteção do sistema climático e o benefício das gerações presentes e futuras da humanidade, evidenciando, dessa forma, o desenvolvimento sustentável. No mesmo sentido, essa proteção deve estar centralizada 
na eqüidade e de acordo com as responsabilidades comuns e diferenciadas dos países partes da convenção (DIAS, 2004).

Outro princípio é o de considerar as necessidades especiais dos países partes em desenvolvimento. A convenção também está consolidada no princípio da precaução, evidenciando a necessária urgência de prever, evitar ou minimizar as causas da alteração climática, mesmo na ausência de absoluta certeza. Ademais, há a previsão do direito ao desenvolvimento sustentável. E enfim, está disposto o dever de cooperação para a promoção de um sistema econômico internacional em conformidade com o crescimento e o desenvolvimento econômico de todas as partes (DIAS, 2004).

A convenção estabelece obrigações para os países integrantes, considerando suas responsabilidades comuns mas diferenciadas. Entre estas obrigações, vale referir a elaboração, atualização periódica e publicação de inventários nacionais de emissões antrópicas e das remoções por sumidouros de todos os gases de efeito estufa. Outra responsabilidade é a inclusão de medidas para minimizar a mudança climática e medidas para adaptação adequada à alteração do clima (DIAS, 2004).

A Convenção também menciona a necessidade de cooperação para o desenvolvimento e inclusive, a transferência de tecnologias, práticas e processos que controlem, reduzam ou previnam as emissões de gases de efeito estufa. Da mesma forma, outra obrigação é a cooperação para o desenvolvimento sustentável e para a conservação dos sumidouros e reservatórios de gases de efeito estufa. A cooperação aos preparativos para possibilitar melhor adaptação aos impactos causados pela mudança climática trata-se de outra responsabilidade (BRASIL, 2007 c).

No mesmo sentido, outra obrigação é a relação entre a mudança do clima e os fatores políticos, sociais, econômicos e ambientais. A cooperação em pesquisas científicas, tecnológicas, técnicas socioeconômicas e outras para a formação de banco de dados acerca da mudança do clima (BRASIL, 2007 c).

Ainda, tem-se como responsabilidade o intercâmbio de informações científicas, tecnológicas, técnicas, socioeconômicas e jurídicas referentes ao sistema climático e à mudança do clima. Outra obrigação é a promoção de treinamento e conscientização acerca da mudança do clima e o estímulo de ampliação da participação nesse processo (BRASIL, 2007 c).

Ademais, como dito outrora, a convenção confere responsabilidades comuns mas diferenciadas para os países partes, estabelecendo um maior número de compromissos para os países desenvolvidos e uma meta de redução menor para os 
países em vias de desenvolvimento.

Desse modo, cabe ressaltar que as responsabilidades atribuídas aos países partes da Convenção sobre Mudança do Clima são diferenciadas em virtude do grau de industrialização de cada Estado e de acordo com a contribuição histórica passada dos países industrializados e dos antigos países do Leste Europeu para o efeito estufa, em comparação com os Estados periféricos (SOARES, 2003).

Em relação às obrigações previstas aos países desenvolvidos, na Convenção, é fundamental entender que essa dissimilitude se dá principalmente em virtude da situação dos Países partes em vias de desenvolvimento, cujas economias são mais vulneráveis aos efeitos negativos das medidas de respostas da mudança climática. Ademais, essa medida proposta na convenção é fundamentada na economia de certos Países periféricos que dependem do consumo de combustíveis fósseis e de produtos afins (BRASIL, 2007 c). Conforme entendimento de George Monbiot:

Most of the rich countries, being located in temperate latitudes, wuill, in the initial stages, at leats, suffer lesser ecological effects. They wuill also have more money with which $t$ protect their citizens from floods, droughts and extremes of temperature. Within these countries, the richeste people, who can buy their way out of trule, wuill be harmed last.(MONBIOT, 2006, p. 21).

Ademais, os Países desenvolvidos e os Países do antigo Leste Europeu são os países que mais contribuíram para a alteração do clima, visto que as emissões per capta são mais elevadas que grande parte dos Países em desenvolvimento e os mesmos dispõem de melhor situação econômica e institucional para resolver o problema da mudança climática (BRASIL, 2007 c).

As Partes desenvolvidas devem assumir a liderança no que tange à estabilização da emissão de gases de efeito estufa e conseqüentemente a minimização das mudanças climáticas, em conformidade com o objetivo da convenção.

Conforme o Ministério da Ciência e Tecnologia:

As Partes do Anexo I compreendem tanto os países relativamente ricos que eram membros da Organização para a Cooperação e o Desenvolvimento Econômicos (OCDE) em 1992, como os países com "economias em transição" (conhecidos como EITs), ou seja, a Federação Russa e vários outros países da Europa Central e Oriental. A Convenção concede "um certo grau de flexibilidade" às EITs na implementação de seus compromissos por causa dos grandes transtornos econômicos e políticos por que passaram esses países. Várias EITs fizeram uso dessa condição para escolher uma linha de base anterior a 1990, ou seja, antes das mudanças econômicas que provocaram grandes reduções nas suas emissões. Os membros da OCDE que são Partes do Anexo I também estão listados no Anexo II da Convenção. Esses países têm a obrigação especial de fornecer 
"recursos financeiros novos e adicionais" aos países em desenvolvimento para auxiliá-los a tratar da mudança do clima, bem como para facilitar a transferência de tecnologias que não causem impactos adversos sobre o clima tanto para os países em desenvolvimento quanto para as EITs (BRASIL, 2007, s p.).

Assim, aos Países do anexo I (Países desenvolvidos e Países do antigo Leste Europeu) ficou disposto o comprometimento com a adoção de políticas nacionais e medidas para reduzir a mudança do clima, no sentido de reduzir a emissão dos gases de efeito estufa e preservar seus sumidouros e reservatórios de gases de efeito estufa (BRASIL, 2007 c).

Outra obrigação das Partes do anexo I é a realização de relatórios periodicamente, acerca das políticas e programas sobre mudança do clima, bem como, a apresentação de inventários anuais sobre as emissões de gases de efeito estufa (BRASIL, 2007 b). Cabe referir ainda, que as Partes desenvolvidas têm o dever de coordenar-se com os outros Países indicados sobre os instrumentos econômicos e administrativos pertinentes para a obtenção do objetivo da convenção. Além disso, devem identificar periodicamente suas próprias políticas e atividades que visam à redução da emissão dos gases de efeitos estufa (BRASIL, 2007 c).

Da mesma maneira, justificando os princípios das responsabilidades comuns mas diferenciadas, bem como, o da eqüidade, os Países desenvolvidos têm como responsabilidade o provimento de recursos financeiros novos e adicionais aos Países em vias de desenvolvimento para cobrir os custos dos mesmos, desde que os custos sejam concordados pelos Países (BRASIL, 2007 c). As Partes desenvolvidas devem também dar auxilio para os Países em vias de desenvolvimento no que se refere aos custos de sua adaptação aos efeitos negativos causados pela mudança climática (BRASIL, 2007 c). Os países em desenvolvimento compõem o grupo dos Países não-Anexo I e cabe a eles a elaboração de relatórios em termos mais gerais acerca das suas ações em relação à alteração climática e à adaptação aos seus efeitos (BRASIL, 2007 b).

A Convenção-Quadro sobre Mudança do Clima estabelece ainda a transferência de tecnologias ecologicamente racionais para os Países periféricos provenientes dos Países desenvolvidos, a fim de proporcioná-los a capacidade de alcançar os objetivos da convenção (BRASIL, 2007 c). Cabe mencionar o argumento no mesmo sentido do Ministério da Ciência e Tecnologia:

A Convenção exige que tecnologias e conhecimentos técnicos ambientalmente saudáveis sejam desenvolvidos e compartilhados. A tecnologia desempenhará, sem dúvida, um papel de grande importância para a mudança do clima. Se nós encontrarmos maneiras práticas de usar fontes de energia mais limpas, como a energia solar, nós poderemos reduzir o consumo de carvão e de petróleo. A 
tecnologia pode tornar os processos industriais mais eficientes, a purificação da água mais viável e a agricultura mais produtiva com a mesma quantidade de recursos investidos. Tal tecnologia deve estar disponível para todos — os países mais ricos e mais avançados cientificamente devem compartilhá-la com países mais pobres que tanto precisam dela (BRASIL, 2007, s p.).

Da mesma forma, esta é a proposta do Painel Intergovernamental para as Mudanças Climáticas, visto que o relatório divulgado, no dia 04 de maio de 2007, mencionou como estratégia para combater o aquecimento global o investimento nas energias renováveis e em outras hipóteses que visem a eficiência energética, o que poderá custar $30 \%$ do PIB mundial até 2030. Evidencia-se, desse modo, a possibilidade de minimizar a emissão dos gases causadores do efeito estufa e do aquecimento global, desde que tenha a cooperação financeira dos Estados possuidores de melhores condições econômicas e tecnológicas (BBC, 2007).

Assim, conforme a disposição do referido organismo, o combate à mudança climática é possível desde que haja o auxílio financeiro e o apoio à inovação tecnológica (IPCC, 2007).

A implementação do mecanismo de desenvolvimento limpo é outra atribuição da convenção em estudo, sendo que para a obtenção da redução do aquecimento global, segundo o relatório do IPCC sobre o clima, é necessário que os Países adotem rapidamente tecnologias que minimizem a emissão de gases de efeito estufa. O relatório menciona como exemplo o aumento do uso de biocombustíveis e de energia nuclear (IPCC, 2007).

A convenção estabelece ainda a necessidade de preservação dos sumidouros. Por sumidouro entende-se a remoção de um gás de efeito estufa, de um aerossol ou de um precursor de um gás de efeito estufa, através de qualquer processo, atividade ou mecanismo (BRASIL, 2007 c).

Trata-se de regiões que acumulam e estocam grandes quantidades de carbono, como as florestas e os fundos oceânicos, que atuam como sumidouros. A redução do desmatamento, como o reflorestamento, por exemplo, poderá contribuir significantemente para a redução do aumento dos gases geradores do efeito estufa, causando outros benefícios, como a conservação dos solos e da biodiversidade. A diminuição do desmatamento deve estar relacionada a circunstâncias econômicas, visando a garantia da qualidade de vida das populações das regiões florestais (ÁRVORES, 2007). 
Destarte, a remoção do carbono da atmosfera promovido pelo crescimento das árvores, através do reflorestamento ou florestamento, evidencia a atuação como sumidouro de carbono ou o "seqüestro de carbono", isto se dá porque a vegetação realiza a fotossíntese, processo em que as plantas retiram carbono da atmosfera e o incorporam a sua biomassa (ÁRVORES, 2007).

A Convenção-Quadro estabelece uma série de mecanismos que visam evitar o aumento da emissão antrópica dos gases de efeito estufa e o conseqüente aquecimento global. Estes mecanismos foram estabelecidos na forma de responsabilidades comuns mas diferenciadas aos Países Partes da Convenção, evidenciando a necessidade de implementação do desenvolvimento sustentável, de mecanismos de desenvolvimento limpo e da transferência de tecnologias, principalmente dos Países desenvolvidos para os Países em vias de desenvolvimento, bem como, a essencial preservação dos sumidouros de carbono.

Entretanto, o conteúdo previsto na convenção não é efetivamente aplicado como o deveria, pois o paradigma atual evidencia uma crise do aquecimento global. Os estudos mais recentes, como o último relatório do Painel Intergovernamental de Mudanças Climáticas, IPCC, demonstram a necessidade e urgência de cooperação de todos os Estados na redução da emissão dos gases causadores do efeito estufa, pretendendo evitar conseqüências mais drásticas ao Planeta Terra.

As conseqüências em relação à potencial mudança climática, ainda não são definidas de forma terminativa, embora muitos estudos já relatem resultados negativos e prováveis que atingirão o Planeta. Conforme o último relatório do Painel Intergovernamental sobre Mudanças Climáticas, o aquecimento global poderá provocar a extinção de cerca de $30 \%$ das espécies do Planeta, considerando um aumento de $2^{\circ} \mathrm{C}$ acima da média dos anos de 1980 e 1990 (IPCC, 2007).

Outra previsão do relatório é a transformação das áreas que sofrem com a falta de chuvas, em áreas ainda mais secas, aumentando o risco de doenças e fome. Há também a previsão de que o mundo enfrentará mais enchentes, tempestades e erosão (IPCC, 2007).

A reunião do IPCC diagnosticou a possibilidade de a África ser o continente mais atingido pela alteração do clima, relatando que a população estará sujeita a falta de água e a produção de alimentos poderá reduzir-se a metade. O relatório ainda previu grandes tempestades, incêndios selvagens e ondas de calor para a América do Norte. Outra previsão foi a ameaça de enchentes e avalanches na Ásia, devido ao derretimento 
das geleiras do Himalaia. O relatório ainda referiu como provável o derretimento das geleiras dos Alpes na Europa, bem como, o desaparecimento de muitos corais na Barreira de Corais da Austrália, em razão do aumento moderado da temperatura do mar (IPCC, 2007).

Em relação à América Latina, poderá haver a perda de $50 \%$ de suas terras agrícolas até o ano de 2050, aparecendo cada vez mais as savanas e a desertificação de terras agrícolas. Outra preocupação é a disponibilidade de água para o consumo e a geração de energia. A ameaça contra determinadas espécies de animais também é veemente, devido principalmente ao aumento do nível do mar, os manguezais e os corais também estão ameaçados pelo mesmo fenômeno (IPCC, 2007). Outra previsão é a possibilidade de alteração dos ecossistemas regionais e a sucessiva perda de um terço das espécies de animais e plantas do Planeta, em virtude do aumento da temperatura, em média, de $1,5^{\circ} \mathrm{C}$ em relação aos anos de 1990 (IPCC, 2007).

O relatório do Painel Intergovernamental sobre Mudanças Climáticas demonstra claramente a necessidade da estabilização da emissão antrópica dos gases causadores do efeito estufa e do aquecimento global. Destarte, é fundamental a implementação de mecanismos eficazes para a obtenção dos objetivos da Convenção-Quadro sobre Mudanças Climáticas, como também, é urgente a participação de todos os países no intuito de evitar a mudança do clima, pois os estudos de gabaritados cientistas, em todo o mundo, prevêem situações catastróficas para o Planeta.

Outro obstáculo de implementação da convenção é a falta de cooperação de determinados países, como os Estados Unidos e a China, que consideram a aplicação da convenção extremamente sacrificante, de intenso impacto na vida cotidiana da população e na economia (SOARES, 2003). No mesmo sentido, as palavras de Geraldo Eulálio do Nascimento e Silva:

[...] A verdade é que, de um modo geral, os principais poluidores do mundo preferiram fazer grossa às recomendações formuladas. Num mundo em que trilhões de dólares são gastos com a aquisição de carvão, petróleo e gás natural e outro tanto com a aquisição de armamentos, os grandes interessados em tais transações não podem encarar favoravelmente o deslocamento de tais recursos para serem utilizados na área ambiental. O pretexto utilizado é que não existem ainda provas conclusivas de que os gases de efeito provoquem o efeito estufa; [...] $(2002$, p. 64).

Destarte, a maior parcela do índice de poluição atmosférica e de proliferação dos gases causadores do efeito estufa, se dá principalmente nesses Estados, em virtude das 
atividades industriais e da emissão dos automóveis. Esses países não dispõem de interesses, principalmente econômicos, para combater a proliferação dos gases de efeito estufa. Esta situação da não cooperação a nível internacional de todos os países é evidenciada em meios de comunicação, como ocorreu com o corte do investimento, em virtude do custo elevado do monitoramento do efeito estufa, que era patrocinado pelos Estados Unidos (CARBONO, 2007).

Destarte, cabe mencionar que é necessário o cumprimento da responsabilização diferenciada pelos Estados no combate à emissão dos gases causadores do efeito estufa, principalmente no que tange ao objetivo de estabilizar a proliferação antrópica dos gases num nível que não cause danos a humanidade.

\section{CONCLUSÃO}

O paradigma do aquecimento global evidencia a necessidade de cooperação de todos os Estados, no que tange à estabilização da emissão dos gases de efeito estufa, em virtude, principalmente, dos efeitos negativos que podem ser gerados pela mudança climática.

Ademais, fundamental é a assistência dos países desenvolvidos aos periféricos, especialmente em relação à transferência de tecnologia, de recursos financeiros e a implementação de mecanismos de desenvolvimento limpo.

A crise do aquecimento exige urgentemente a colaboração de todos os Estados, visto que se trata de um problema potencialmente nocivo para toda a humanidade e o meio ambiente global, independente dos interesses de cada país em relação a efetividade da convenção sobre mudança do clima.

\section{REFERENCIAS}

AMENIZAR efeito estufa custa 3\% do pib mundial. Bbc Brasil. Disponível em: $<$ http://www.bbc.co.uk/portuguese/reporterbbc/story/2007/05/070504_ipccmarinaebc.sh

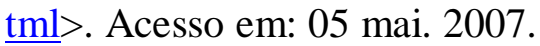

BRASIL. Comissão Interministerial de Mudança Global do Clima. Disponível em: <http://200.130.9.7/clima/cigmc/exmotivo.htm>. Acesso em: 27 mai. 2007.

BRASIL. Conferência do Rio de Janeiro sobre Meio Ambiente e desenvolvimento. Disponível em:

<http://www.interlegis.gov.br/processo legislativo/copy of 20020319150524/2003062 5102846/20030625104533/>. Acesso em: 15 mai. 2007.

BRASIL. Convenção-Quadro das Nações Unidas sobre Mudanças Climáticas. Disponível em: <http://www.mct.gov.br/index.php/content/view/4069.html>. Acesso em: 25 mai. 2007. 
DIAS, Edna Cardoso. Convenção do Clima. Disponível em: <http://jus2.uol.com.br/doutrina/texto.asp?id=5600〉. Acesso em: 27 abr. 2007. EUA cortam investimento em monitoração do efeito estufa. Carbono Brasil.

Disponível em: 〈http://carbono.isnet.com.br/news.htm?id=191630\&section=5 > . Acesso em: 28 mai. 2007.

IPCC. Intergovernamental Panel Climate Change. Disponível em:

<http://www.ipcc.ch/index.html>. Acesso em: 29 mai. 2007.

REFLORESTAMENTO sequestro de carbono. Árvores Brasil. Disponível em:

<http://209.85.165.104/search?q=cache:smfq4qTbjIQJ:www.arvoresbrasil.com.br/\%3F pg\%3Dreflorestamento sequestro+preserva\%C3\% A7\%C3\% A3o+dos+sumidouros+de+ gases+de+efeito+estufa\&hl=pt-BR\&ct=clnk\&cd=16\&gl=br >. Acesso em: 05 jun. 2007. 